\title{
Spatial extent and ecotoxicological risk assessment of a micropollutant-contaminated wastewater plume in Lake Geneva
}

\author{
Corinne C. Hoerger · Yosef Akhtman - Lorenzo Martelletti - Rebecca Rutler • \\ Florence Bonvin · Aureline Grange $\cdot$ J. Samuel Arey $\cdot$ Tamar Kohn
}

Received: 19 December 2012/ Accepted: 16 September 2013/Published online: 10 October 2013

(C) Springer Basel 2013

\begin{abstract}
In this study, the spatial extent of a wastewaterinfluenced water mass (plume) originating from a wastewater treatment plant outlet in Vidy Bay (Lake Geneva) was monitored by two manned submersibles from June to August 2011. The main goal was to assess whether micropollutants in the wastewater mass cause an ecotoxicological risk to the aquatic environment, and to determine how far the zone of risk extends beyond the wastewater outlet. Real-time measurements of elevated electrical conductivity were used as a proxy to indicate the presence of wastewater-influenced water. Conductivity was
\end{abstract}

This article is part of the special issue "éLEMO - investigations using MIR submersibles in Lake Geneva".

Electronic supplementary material The online version of this article (doi:10.1007/s00027-013-0315-6) contains supplementary material, which is available to authorized users.

C. C. Hoerger · R. Rutler · F. Bonvin · T. Kohn ( $\square)$ Environmental Chemistry Laboratory (LCE), Environmental Engineering Institute (IIE), School of Architecture, Civil and Environmental Engineering (ENAC), Ecole Polytechnique Fédérale de Lausanne (EPFL), Station 2, 1015 Lausanne, Switzerland

e-mail: tamar.kohn@epfl.ch

Y. Akhtman · L. Martelletti

Geodetic Engineering Institute (TOPO), Environmental Engineering Institute (IIE), School of Architecture, Civil and Environmental Engineering (ENAC), Ecole Polytechnique Fédérale de Lausanne (EPFL), Station 2, 1015 Lausanne, Switzerland

\section{A. Grange · J. S. Arey}

Environmental Chemistry Modeling Laboratory (LMCE), Environmental Engineering Institute (IIE), School of Architecture, Civil and Environmental Engineering (ENAC), Ecole Polytechnique Fédérale de Lausanne (EPFL), Station 2, 1015 Lausanne, Switzerland highest in immediate proximity to the wastewater outlet, though if all measurements obtained over the duration of the sampling campaign were integrated, elevated conductivity extended over an area of at least $1 \mathrm{~km}^{2}$ surrounding the outlet. Additionally, water samples were collected within and outside Vidy Bay, and were analyzed for 39 micropollutants (pharmaceuticals, pesticides, and corrosion inhibitors). Micropollutant concentrations were generally in the low $\mathrm{ng} / \mathrm{L}$ range, though for some substances $>100 \mathrm{ng} / \mathrm{L}$ was measured. The concentrations of most pharmaceuticals, which are primarily wastewater-derived, decreased with decreasing conductivity and with increasing distance from the wastewater outlet. Pesticide concentrations, in contrast, were homogeneous throughout Vidy Bay and the lake. An ecotoxicological risk assessment based on the cumulative risk exerted by all measured substances indicated that the wastewater caused a zone of potential

\author{
A. Grange · J. S. Arey \\ Department of Environmental Chemistry, Swiss Federal Institute \\ of Aquatic Sciences and Technology (Eawag), Überlandstrasse \\ 133, 8600 Dubendorf, Switzerland \\ Present Address: \\ C. C. Hoerger \\ Laboratory for Air Pollution and Environmental Technology, \\ Swiss Federal Laboratories for Materials Science and \\ Technology (Empa), Ueberlandstrasse 129, 8600 Duebendorf, \\ Switzerland \\ Present Address: \\ L. Martelletti \\ Pix4D, Chemin de la Venoge 11, 1024 Ecublens, Switzerland \\ Present Address: \\ R. Rutler \\ Cimo Compagnie industrielle de Monthey SA (CIMO), Case \\ Postale 432, 1870 Monthey, Switzerland
}


ecotoxicological risk that extended well into the deep lake and in the direction of a downstream drinking water intake.

Keywords Risk quotient - Pharmaceuticals - Pesticides · Corrosion inhibitors · Wastewater mass .

Electrical conductivity

\section{Introduction}

A large variety of natural and man-made substances are present in aquatic environments, mainly resulting from surface runoff and from the input of municipal and industrial wastewaters (Daughton and Ternes 1999; Kolpin et al. 2002; Kuemmerer 2010). This includes residues of natural toxins (Hartmann et al. 2007; Hoerger et al. 2009; Schenzel et al. 2010) and pesticides (Stoob et al. 2005) from agricultural sources, as well as pharmaceuticals and personal care products from municipal use and industrial production (Daughton and Ternes 1999; Oulton et al. 2010). These so-called micropollutants are mostly detected and quantified at low concentrations (e.g. $\mathrm{ng} / \mathrm{L}$ to $\mu \mathrm{g} / \mathrm{L}$ ). To date, the occurrence and fate of micropollutants discharged from wastewater treatment plants (WWTPs) have been principally investigated in rivers (Tixier et al. 2003). Only a few studies have reported the occurrence and fate of micropollutants from WWTPs directly discharging to lakes (Metcalfe et al. 2003; Morasch et al. 2010; Perazzolo et al. 2010; Bonvin et al. 2011).

When wastewater is discharged into a large water body, it can be rapidly diluted by the surrounding water masses. During periods of stratification (e.g. in summer), however, mixing of the water masses is limited due to the stable temperature gradient throughout the water column. The wastewater mass therefore will spread laterally, rise or sink until its density corresponds to that of the surrounding water masses (Tian et al. 2006). This wastewater mass is dispersed throughout the water body by horizontal, advective currents.

The dispersion and dilution of sewage effluents has been investigated in several studies by means of tracer experiments (Sinton and Ching 1987; Vandenberg et al. 2005; Benotti and Brownawell 2007). Common wastewater tracers include intrinsic microbiological, physical, and chemical indicators, such as bacteria, electrical conductivity or salinity, or added tracers such as fluorescent dyes (Carvalho et al. 2002). In addition to these parameters, the introduction of sewage into surface water is also characterized by elevated micropollutant concentrations. Micropollutants in a wastewater-influenced water mass situated in Vidy Bay (Lake Geneva) were first reported by Bonvin et al. $(2011,2012)$. The concentrations of pharmaceuticals, pesticides, and corrosion inhibitors had a range between few ng/L to few $\mu \mathrm{g} / \mathrm{L}$. Along with the discharge of micropollutants, elevated electrical conductivity arising from simultaneous introduction of macropollutants (such as nitrate, sulfate, or chloride) into the lake was observed near the WWTP outlet. Consequently, a correlation between micropollutants derived from the WWTP and electrical conductivity was observed, indicating that wastewater-derived increases in conductivity may serve as a proxy for micropollutant contamination.

Lake Geneva is one of the largest freshwater resources of Western Europe. As such, it serves as a drinking water source for over half a million inhabitants of the surrounding area. Along with several other WWTPs, the centralized Lausanne WWTP discharges more than $100,000 \mathrm{~m}^{3}$ of treated wastewater per day into Lake Geneva's Vidy Bay at $30 \mathrm{~m}$ depth, $700 \mathrm{~m}$ offshore (Fig. 1). As the sewage treatment methods employed by the Vidy WWTP only incompletely eliminate micropollutants (Morasch et al. 2010), several pharmaceuticals, pesticides, and other anthropogenic substances were detected in the Bay throughout the year in the low to high $\mathrm{ng} / \mathrm{L}$ range (Bonvin et al. 2011; Morasch et al. 2010). These concentrations were particularly elevated during the warmer seasons, when lake stratification led to the presence of a wastewaterinfluenced water mass above the WWTP outlet. Notably, several antibiotic substances in this water were present at concentrations that constitute a potential ecotoxicological risk (Bonvin et al. 2011). At a reference sampling point located $1.5 \mathrm{~km}$ downstream of the WWTP outlet, micropollutant concentrations had typically decreased to background levels due to dilution, dispersion, and environmental elimination processes. The extent of the wastewater-influenced water mass between the WWTP outlet and the reference point, however, was not investigated. Accordingly, it is not known how far the ecotoxicological risk exerted by the micropollutants in the wastewater-influenced water mass expands beyond the WWTP outlet. The goal of this work was thus to trace the wastewater-influenced water mass in different points in Vidy Bay surrounding the WWTP outlet, with the goal of establishing its spatial extent.

In summer 2011, nearly 60 dives with two submersibles (MIRs) were performed in different parts of Lake Geneva (Wüest et al. 2013). Given the agility and range of these submersibles, this was a unique opportunity to map the wastewater dispersion in Vidy Bay. In addition to tracing conductivity as a wastewater indicator, water samples were collected during five dives in and around Vidy Bay and analyzed for the presence of 39 micropollutants (Table 1). The substances considered are known to be incompletely removed during wastewater treatment, as they are poorly biodegradable (except paracetamol) and highly soluble. Furthermore, based on consumption and metabolism data, 
Fig. 1 Spatial variation of electrical conductivity in a Lake Geneva and b Vidy Bay. The scale indicates the deviation of the instantaneous values from the depth-specific background average values following the methodology described in the Sect. "Materials and methods". Dot size scales with sample depth, with larger dots indicating deeper samples. The flag indicates the site of the WWTP outlet (color figure online)
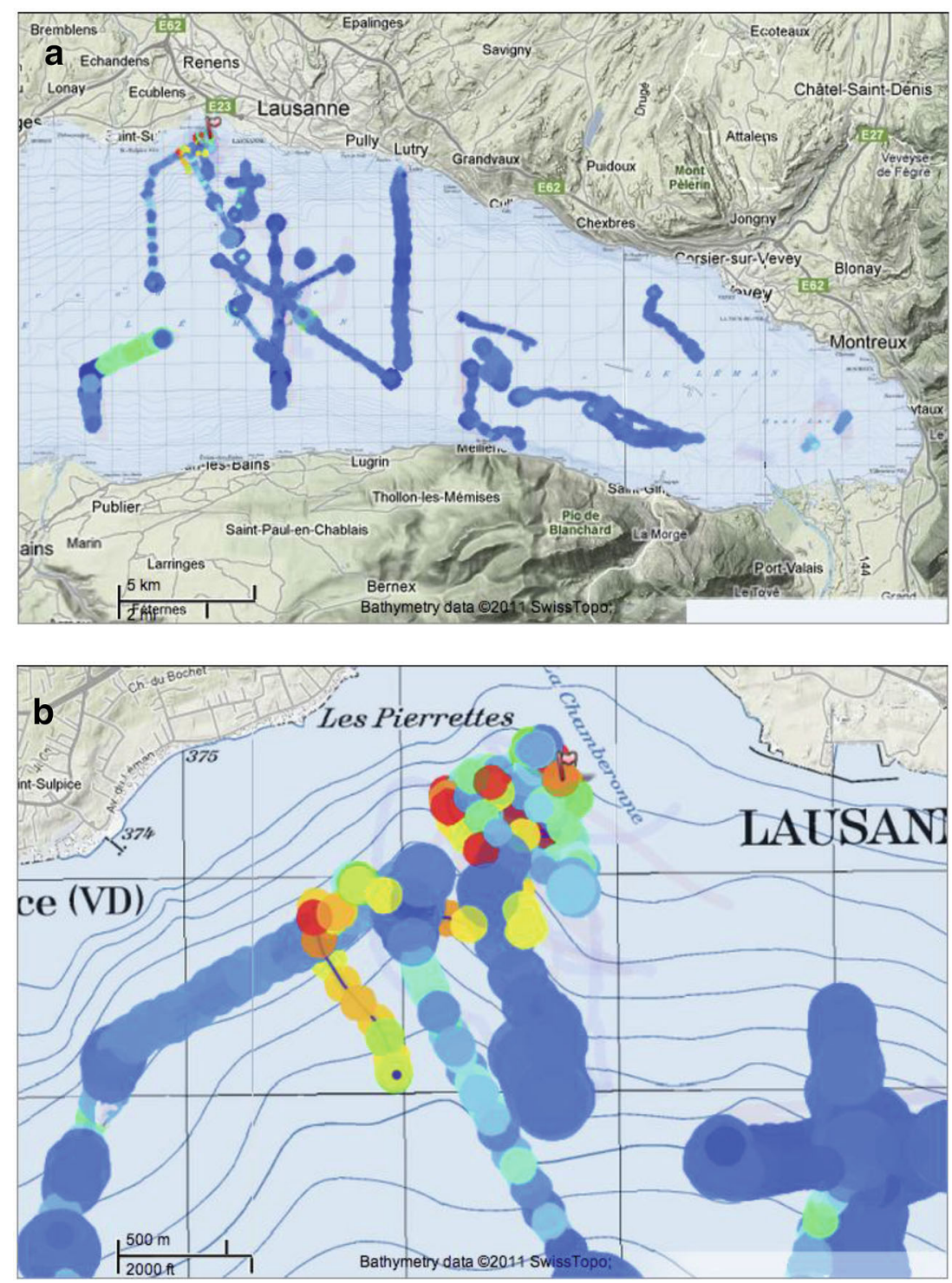

Depth-normalized deviation from the background conductivity [ $u$ ]
2.5 as well as-if known-their ecotoxicological impact, these substances were identified as priority substances for the Lake Geneva region (Perazzolo et al. 2010). The ecotoxicological risk resulting from the wastewater was assessed, considering both the toxicity of the individual compounds, as well as the toxicity of micropollutant mixtures (Backhaus et al. 2003; Backhaus and Faust 2012). In the latter case, the concept of concentration addition was applied as a worst case.

The results presented herein encompass several wastewater dispersion situations recorded from June to August 2011. They reflect typical scenarios encountered in the stratified lake. These results cannot be generalized for the whole year because the mixing dynamics in Lake Geneva are strongly dependent on the season (e.g. stratification of the lake during summer, mixing during winter; Thorpe et al. 1999; Umlauf and Lemmin 2005; Goldscheider et al. 2007; Poté et al. 2008).

\section{Materials and methods}

\section{Conductivity measurements}

In different parts of Lake Geneva (Vidy Bay, Grand Lac, and Rhone Delta), electrical conductivity was recorded real-time by a CTD (conductivity, temperature, and depth) instrument (SBE 19plus, Sea-Bird Electronics Inc., USA). The CTD was calibrated at the beginning of the field campaign; it typically does not require further calibration, 
Table 1 Summary of the analyzed micropollutants and their application, the limits of detection, numbers and frequency of detection, the predicted no effect concentration, the number of times that the risk quotient (RQ) exceeded the value of 0.1 and 1 , respectively, and the most sensitive species for which ecotoxicological tests were performed

\begin{tabular}{|c|c|c|c|c|c|c|c|}
\hline $\begin{array}{l}\text { Analyzed } \\
\text { micropollutants } \\
\text { (application) }\end{array}$ & $\begin{array}{l}\text { Limit of } \\
\text { detection } \\
(\mathrm{ng} / \mathrm{L})^{\mathrm{a}}\end{array}$ & $\begin{array}{l}\text { No detected (out } \\
\text { of } 34 \text { samples } \\
\text { analyzed) }\end{array}$ & $\begin{array}{l}\text { Frequency } \\
\text { of detection } \\
(\%)\end{array}$ & $\begin{array}{l}\text { Predicted no effect } \\
\text { concentration } \\
(\mathrm{PNEC})(\mathrm{ng} / \mathrm{L})^{\mathrm{a}}\end{array}$ & $\begin{array}{l}\text { No of occurrences } \\
\text { of RQ between } \\
0.1 \text { and } 1\end{array}$ & $\begin{array}{l}\text { No of } \\
\text { occurrences } \\
\text { of } R Q>1\end{array}$ & $\begin{array}{l}\text { Most } \\
\text { sensitive } \\
\text { species }^{b}\end{array}$ \\
\hline Atenolol (beta blocker) & 1.3 & 34 & 100 & 33,400 & 0 & 0 & $\mathrm{C}$ \\
\hline Atrazine (herbicide) & 1.3 & 34 & 100 & 420 & 0 & 0 & A \\
\hline Azithromycin (antibiotic) & 1.3 & 12 & 35.3 & 10 & 10 & 2 & A \\
\hline Benzotriazole (corrosion inhibitor) & 6.6 & 34 & 100 & 30,000 & 0 & 0 & $\mathrm{C}$ \\
\hline Bezafibrate (anticholesterol) & 1 & 8 & 23.5 & 1,191 & 0 & 0 & $\mathrm{C}$ \\
\hline Carbamazepine (antiepileptic) & 1.3 & 34 & 100 & 2,500 & 0 & 0 & $\mathrm{C}$ \\
\hline Carbendazim (fungicide) & 1.8 & 34 & 100 & 100 & 24 & 0 & $\mathrm{C}$ \\
\hline Chloridazon (herbicide) & 0.7 & 28 & 82.4 & 97 & 0 & 0 & A \\
\hline Ciprofloxacin (antibiotic) & 2.1 & 6 & 17.6 & 5 & 0 & 6 & A \\
\hline Clarithromycin (antibiotic) & 0.6 & 32 & 94.1 & 60 & 6 & 0 & CB \\
\hline Clindamycin (antibiotic) & 1.1 & 23 & 67.6 & Not available & - & - & - \\
\hline Diclofenac (analgesic) & 1.8 & 27 & 79.4 & 100 & 21 & 2 & $\mathrm{~F}$ \\
\hline Gabapentin (antiepileptic) & 2.2 & 25 & 73.5 & 100,0000 & 0 & 0 & $\mathrm{C}$ \\
\hline Gemfibrocil (anticholesterol) & 2.2 & 10 & 29.4 & 751,000 & 0 & 0 & $\mathrm{C}$ \\
\hline Irgarol (herbicide, algicide) & 1.6 & 1 & 2.9 & 1.6 & 0 & 1 & A \\
\hline Ketoprofen (analgesic) & 2 & 5 & 14.7 & 15,600 & 0 & 0 & A \\
\hline Mecoprop (herbicide) & 2.1 & 34 & 100 & 1,000 & 0 & 0 & M \\
\hline $\begin{array}{l}\text { Methylbenzotriazole } \\
\text { (corrosion inhibitor) }\end{array}$ & 1.3 & 34 & 100 & 75,000 & 0 & 0 & A \\
\hline Metoprolol (beta blocker) & 0.7 & 34 & 100 & 3,200 & 0 & 0 & $\mathrm{C}$ \\
\hline Metronidazol (antibiotic) & 1.4 & 8 & 23.5 & 25,000 & 0 & 0 & A \\
\hline Norfloxacin (antibiotic) & 1.9 & 1 & 2.9 & 40,100 & 0 & 0 & A \\
\hline Ofloxacin (antibiotic) & 1.4 & 21 & 61.8 & 500 & 0 & 0 & A \\
\hline Paracetamol (analgesic) & 3.6 & 10 & 29.4 & 9,200 & 0 & 0 & $\mathrm{C}$ \\
\hline Primidon (antiepileptic) & 2.0 & 21 & 61.8 & 54,171 & 0 & 0 & $\mathrm{C}$ \\
\hline Propiconazol (fungicide) & 0.7 & 34 & 100 & 1,220 & 0 & 0 & A \\
\hline Propranolol (beta blocker) & 0.9 & 6 & 17.6 & 50 & 1 & 0 & $\mathrm{~F}$ \\
\hline Sotalol (beta blocker) & 1.3 & 16 & 47.1 & 15,935 & 0 & 0 & $\mathrm{C}$ \\
\hline Sulfamethoxazole (antibiotic) & 1.1 & 34 & 100 & 26.8 & 33 & 1 & A \\
\hline Terbutryn (herbicide, algicide) & 1.2 & 33 & 97.1 & 40 & 3 & 0 & A \\
\hline Trimethoprim (antibiotic) & 1.1 & 28 & 82.4 & 160,000 & 0 & 0 & A \\
\hline
\end{tabular}

Additionally, the most sensitive species are reported

${ }^{\text {a }}$ From (Bonvin et al. 2011)

${ }^{\mathrm{b}} \mathrm{A}=$ algae, $\mathrm{C}=$ crustaceans, $\mathrm{CB}=$ cyanobacteria, $\mathrm{M}=$ macrophytes, $\mathrm{F}=$ fish

and has a relative measurement accuracy of $<1 \mu \mathrm{S} / \mathrm{cm}$ (personal communications B. Wehrli and A. Wüest).

\section{Interpretation and visualization of conductivity data}

The nature of the collected conductivity data poses a considerable challenge in terms of the required statistical analysis to depict conductivity differences. Specifically, the data were collected along a one-dimensional trajectory within a large three-dimensional body of water. Furthermore, the collected conductivity data have significant depth-dependent variability both in their mean value, as well as the corresponding variance. As a result, the collected dataset constitutes a fairly sparse sample of the total distribution with only a small number of values recorded at each depth and at each location. Our aim therefore was to devise an analysis methodology that would maximize the reuse of the available data at each geographic location, regardless of the depth at which the samples were recorded. Correspondingly, we formulated a variable ( $u$, see below), which serves as a depth-invariant indicator of the deviation of the recorded conductivity from background values. In 
addition to the depth invariance, this indicator had to take into account the non-uniform nature of the collected samples, such that the devised statistics would not be biased by the arbitrary characteristics of the data collection process (e.g., the speed of the submersible).

To visualize the electrical conductivity gradients in Vidy Bay compared to the rest of Lake Geneva, a background conductivity in the Grand Lac region was calculated as follows: firstly, the volume of the lake was divided into volumetric cells of $100 \times 100 \times 1$ meters, as depicted in figure $\mathrm{S} 1$, where the three dimensions correspond to the CH1903 Swiss grid easting's, northing's and depth, respectively, while the red line represents the trajectory of the submersible through the water column. The cell average value for the recorded conductivity was calculated using all of the values obtained in each particular cell over the duration of the entire field campaign, and the resultant value was assigned to the corresponding cell as the cell expectation value $\left(V_{x, y, z}\right)$ as follows.

$V_{x, y, z}=\frac{1}{N} \sum_{v} v$

where $v$ denotes the instantaneous value recorded, $\mathrm{N}$ is the number of measurements within $\mathrm{C}_{\mathrm{x}, \mathrm{y}, \mathrm{z}}$, the volumetric cell located at coordinates $(x, y, z)$.

Subsequently, the background values $\bar{V}_{z}$ were calculated for each depth in one meter increments as the average over the set of expectation values for the cells located at the corresponding depth yielding.

$\bar{V}_{z}=\frac{1}{M} \sum_{(x, y) \text { in } R} V_{x, y, z}^{\text {background }}$

where $V_{x, y, z}^{\text {background }}$ refers to the average conductivity in cells located in the region of the Grand Lac designated as the background region (Supporting Information, Figure S2), $R$ represents the deepest portion of the Grand Lac region of the lake, and $\mathrm{M}$ is the number of cells containing the measured samples. Division by $\mathrm{M}$ ensured that all cells had the same contribution to the overall statistical analysis, regardless of the sample density within each cell.

Likewise, the standard deviation of $\bar{V}_{z}, \bar{\sigma}_{z}$ was calculated for each depth in one meter increments and using the set of expected values in the corresponding volumetric cells located in the background portion of the lake indicated in figure S2.

$\overline{\sigma_{z}}=\left(\frac{1}{M} \sum_{(x, y) \text { in } R}\left(V_{x, y, z}^{\text {background }}-\overline{V_{z}}\right)^{2}\right)^{1 / 2}$

Finally, we define $u$ as the normalized deviation from the background. It was used for the sake of visualization of the electrical conductivity, and was calculated as the normalized deviation of any instantaneous value $v$ from the background mean value $\bar{V}_{z}$ at the corresponding depth, such that the actual visualized quantity may be expressed as.

$u=\frac{v-\overline{V_{z}}}{\overline{\sigma_{z}}}$

A detailed description of the methodology used to organize and visualize multi-modal data collected in the course of the éLEMO project's underwater field campaign is presented in Akhtman et al. (2012).

\section{Micropollutant sampling}

Lake water samples for micropollutant analysis were obtained in 34 locations and at different depths in and close to Vidy Bay (Northern shore of Lake Geneva). Besides the Chamberonne River, the major water input into Vidy Bay is the effluent discharge from Lausanne's WWTP located $700 \mathrm{~m}$ from shore at $30 \mathrm{~m}$ depth. In addition, the Venoge River flows into the lake approximately $1 \mathrm{~km}$ west of Vidy Bay and the Vuachère River $1 \mathrm{~km}$ to its east. During the summer of 2011, water samples were collected at various depths and locations in Vidy Bay on June 21, July 8 and 19, and August 4 and 16. The trajectories of the corresponding dives are shown in the Supporting Information (Figure S3). Samples were collected with a rosetta water sampler (1018 Rosette Sampling System, General Oceanics Inc., USA) equipped with 11 Niskin bottles $(1.7 \mathrm{~L})$ mounted to the submersible. On August 4, sampling was performed with four independent Niskin bottles instead of the rosetta. During the dives, the submersible logged coordinates and depths in real-time. In addition, the CTD logged the electrical conductivity and temperature at the sampling points.

\section{Micropollutant analysis}

Sample preparation and analysis of 39 micropollutants were made as described in detail previously (Bonvin et al. 2011; Morasch et al. 2010). In brief, one liter lake water samples (acidified to $\mathrm{pH} 2$ with hydrochloric acid) were filtered through $<1 \mu \mathrm{m}$ glass fiber filters (Whatman). All filtrates were spiked with 20 deuterated standards to account for losses during sample treatment. The 39 target compounds were subsequently passed through handassembled $6 \mathrm{~mL}$ cartridges using an automated solid phase extraction (SPE) system (GX-274 ASPEC, Gilson), eluted and evaporated to $200 \mu \mathrm{L}$. Extracts were stored at $-20{ }^{\circ} \mathrm{C}$ until analysis and quantification by UPLC-MS/MS (ultra performance liquid chromatography coupled to a tandem mass spectrometer; Acquity UPLC system, Waters). Prior to analysis, stored samples were diluted 1:1 with UPLC eluent and analyzed twice by UPLC-MS/MS. Reported values represent the average of the two separate measurements. The overall uncertainty associated with the entire 
extraction, analysis and quantification procedure ranged from 6 to $51 \%$ (Bonvin et al. 2011).

\section{Ecotoxicological risk assessment}

The ecotoxicological risk was assessed by comparing the measured environmental concentrations (MEC) with predicted no-effect concentrations (PNEC; the concentration below which an adverse ecotoxicological effect is not expected) defined for individual substances. The resulting risk quotient (RQ), which corresponds to the ratio of the MEC/PNEC, must remain below unity to ensure an acceptable risk to the environment (Chevre et al. 2006). The PNECs for the investigated micropollutants were reported in Bonvin et al. (2011) and are shown in Table 1. RQs were calculated for individual substances as well as for micropollutant mixtures. In the latter case, the concept of concentration addition was applied as a worst case (Backhaus et al. 2003; Backhaus and Faust 2012). This concept implies that the effects of compounds (in a mixture) with a similar mode of action are additive. The RQ of a mixture of compounds can therefore be calculated as the sum of the RQs of the individual compounds.

Correlation of conductivity and micropollutants

Micropollutant concentrations at each sampling point in the wastewater-influenced mass were correlated to conductivity by means of linear regression. An analysis of covariance was performed to evaluate whether the correlation between micropollutant concentrations and electrical conductivity were comparable to those of Bonvin et al. (2011). The differences in analysis of covariance were considered significant at a $p$ value of $\leq 0.05$.

\section{Results and discussion}

Spatial variation of electrical conductivity

The spatial variation of conductivity is depicted for the whole lake and Vidy Bay in Fig. 1. In general, conductivity in the middle of the lake and in the Rhone Delta (Eastern part of Lake Geneva) was similar to the calculated background conductivity, which had a range of 280 to $300 \mu \mathrm{S} /$ $\mathrm{cm}$, depending on the measurement depth (blue dots in Fig. 1). In contrast, higher conductivity with values up to $380 \mu \mathrm{S} / \mathrm{cm}$ was measured in Vidy Bay (green, yellow, orange, and red dots in Fig. 1b), in particular at shallow depths. This elevated conductivity in Vidy Bay is mainly attributed to the influx of wastewater, which has an average conductivity of $1,000 \mu \mathrm{S} / \mathrm{cm}$. The contribution of the Chamberonne, Vuachère, and Venoge rivers, in contrast, is only minor, as their conductivities $(\sim 400 \mu \mathrm{S} / \mathrm{cm})$ are lower than that of the treated wastewater, whereas their average discharge during the summer months is comparable to (Chamberonne and Venoge) or less than (Vuachère) that of the WWTP (Coutu et al. 2012; http://www. hydrodaten.admin.ch/en/2432.html\#historische_daten (accessed May 2013), http://www.vhv.ch/ (accessed May 2013)). The area with elevated conductivity was thus considered to correspond to a wastewater-influenced water mass.

During the sampling period, the wastewater-influenced water mass had a cumulative spatial extent of at least $1.5 \mathrm{~km}$ in North-South- and $2 \mathrm{~km}$ in East-West-direction of the discharge of the WWTP (Fig. 1b).

\section{Occurrence of micropollutants in Vidy Bay}

During the five sampling days in Vidy Bay, 21 pharmaceuticals, seven pesticides, and two corrosion inhibitors were detected. The pharmaceuticals atenolol, carbamazepine, metoprolol, and sulfamethoxazole were detected in all 34 samples. The frequency of detection was more than $50 \%$ for clarithromycin $(94.1 \%)$, trimethoprim $(82.4 \%)$, diclofenac $(79.4 \%)$, gabapentin $(73.5 \%)$, clindamycin $(67.6 \%)$, ofloxacin $(61.8 \%)$, and primidon $(61.8 \%)$. The other pharmaceuticals sotalol $(45.1 \%)$, azithromycin (35.3\%), gemfibrocil (29.4\%), paracetamol (29.4\%), bezafibrate $(23.5 \%)$, metronidazol $(23.5 \%)$, ciprofloxacin $(17.6 \%)$, propranolol $(17.6 \%)$, ketoprofen $(14.7 \%)$, and norfloxacin $(2.9 \%)$ were detected less frequently. Paracetamol was quantified at the highest concentration $(187 \mathrm{ng} / \mathrm{L})$. On average, however, most pharmaceuticals were detected in the low ng/L-concentration range (Fig. 2a; Table 1). Figure $2 b$ shows the corresponding RQ (ratio between MEC and PNEC) for the individual pharmaceuticals. For azithromycin, ciprofloxacin, diclofenac, and sulfamethoxazole, ratios above unity were obtained. In contrast, gemfibrocil and trimethoprim had the lowest RQs $(\leq 0.00001)$.

Among the non-pharmaceuticals, the pesticides, atrazine, carbendazim, mecoprop, propicanazol, and the corrosion inhibitors, benzotriazole and methylbenzotriazole, were detected in $100 \%$, and terbutryn, chloridazon, and irgarol were found in 97.1, 82.4, and $2.9 \%$, respectively, of all samples. As for pharmaceuticals, pesticides were detected on average in the low $\mathrm{ng} / \mathrm{L}$-concentration range, whereas both corrosion inhibitors were quantified at higher average concentrations (377 and $50 \mathrm{ng} / \mathrm{L}$ for benzotriazole and methylbenzotriazole, respectively; Fig. 2c; Table 1). The RQ for individual pesticides and corrosion inhibitors are depicted in Fig. 2d. Only irgarol reached a value of 1 . All other compounds had values below unity.

Similar concentration patterns were previously observed for pharmaceuticals, pesticides, and corrosion inhibitors in 

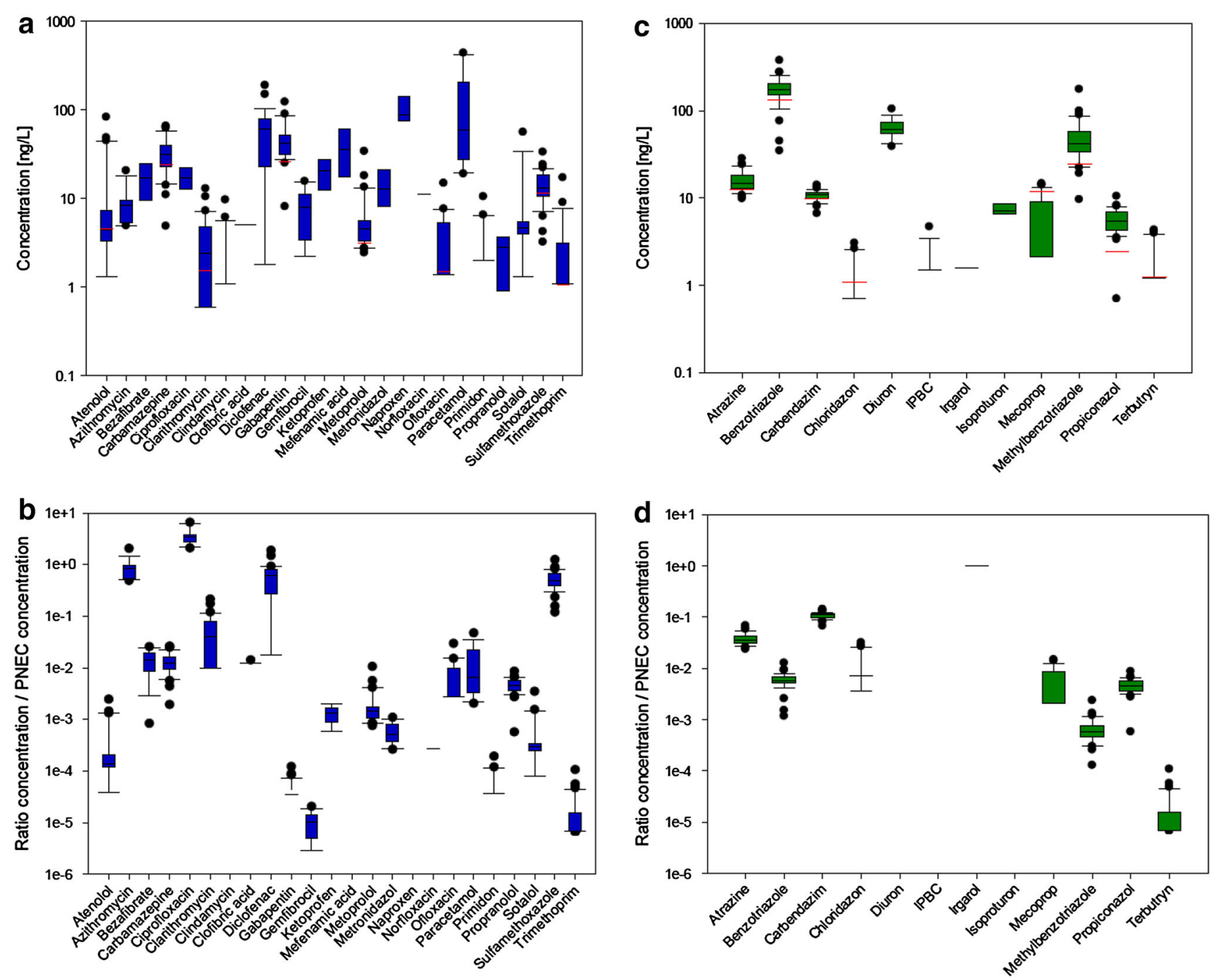

Fig. 2 Concentrations (ng/L) and ratio between concentration and PNEC (on a log scale) of investigated pharmaceuticals (a, b) and pesticides and corrosion inhibitors (c, d), respectively, in Vidy Bay, Lake Geneva. Boxes encompass median, 25th and 75th percentiles,

Vidy Bay (Morasch et al. 2010; Bonvin et al. 2011, 2012). A comparison of our data with micropollutant concentrations in another Swiss lake-Greifensee-shows that the concentrations of benzotriazole (Giger et al. 2006) and carbamazepine (Tixier et al. 2003) in both lakes were comparable. For diclofenac, the concentrations detected in Greifensee were similar to those measured by Tixier et al. (2003) or lower than those measured by Buser et al. (1998) and Poiger et al. (2001), whereas the concentration of the herbicide metolachlor was higher (Huntscha et al. 2008). Given the greater fraction of agricultural area in the catchment of Greifensee compared to Lake Geneva, the high concentration of this herbicide is not surprising.

To elucidate the spatial distribution and concentration pattern of pharmaceuticals and pesticides, we compared the micropollutant concentrations in samples taken in and near

error bars the 95 th and 5 th percentiles, and dots indicate outliers. The red dashes in a and $\mathbf{c}$ indicate the background concentrations. Where no red dash is reported, the background concentration was below the detection limit (color figure online)

Vidy Bay to the background concentration. The background concentrations, indicated as red bars in Fig. 2a and c, were calculated as the average of two samples obtained during dive number 2 (July 8, 2011) located well outside Vidy Bay. In Figs. 3a-f and $4 a-b$, the difference to the background concentrations of selected pharmaceuticals (sulfamethoxazole, azithromycin, ciprofloxacin, diclofenac, paracetamol, and carbamazepine) and pesticides (atrazine and mecoprop) are depicted. The background concentrations are represented by the color corresponding to a value of 0 on the scale below the individual figures. Most pharmaceuticals have a similar spatial distribution and pattern: near the WWTP outlet, the concentrations were higher compared to sampling points closer to Vidy Bay, where they were often comparable to the background level. A notable outlier was the outermost sampling point in the case of diclofenac 

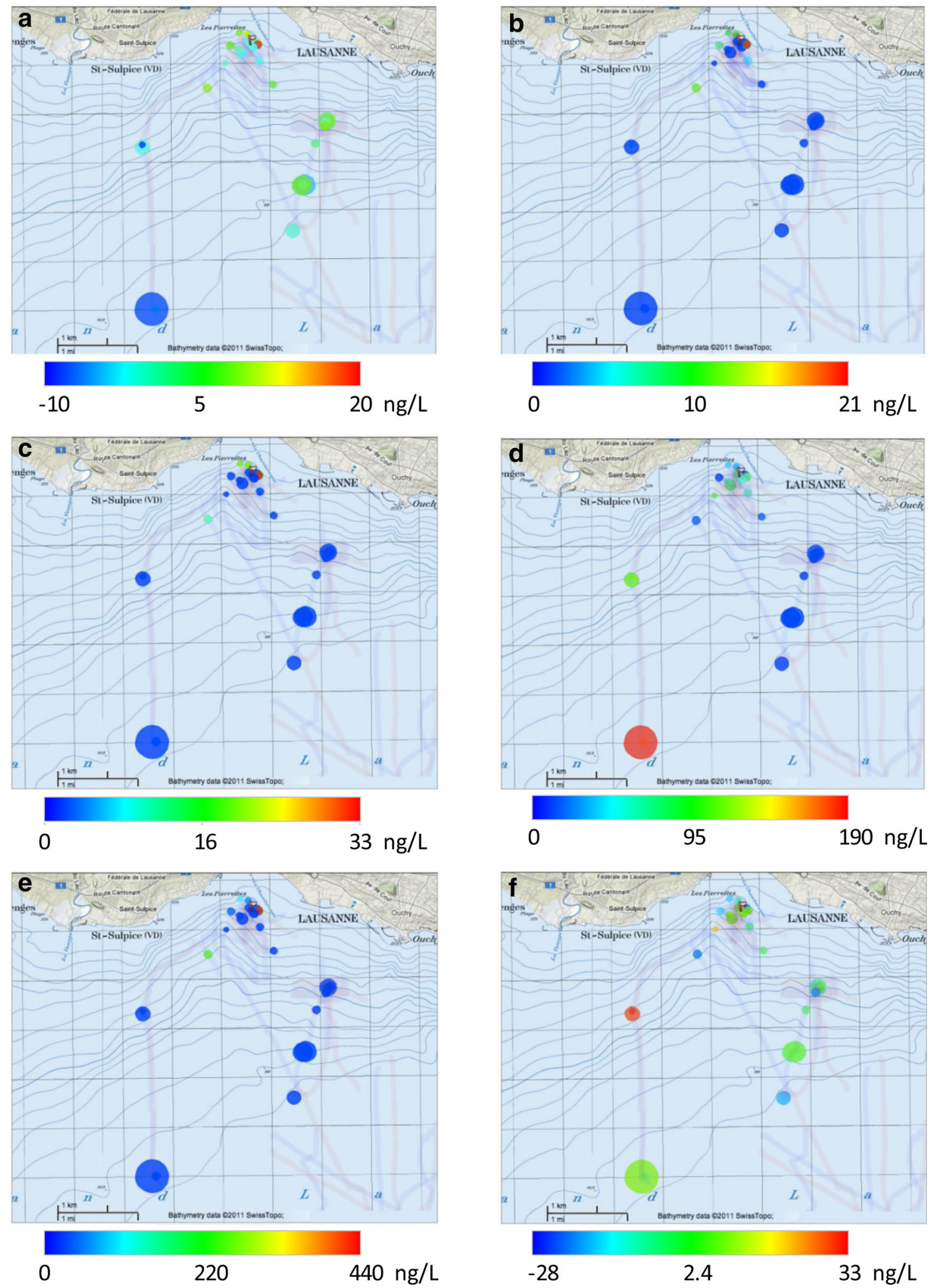

Fig. 3 Difference between measured concentration and background concentration (ng/L) for pharmaceuticals: a sulfamethoxazole, $\mathbf{b}$ azithromycin, c ciprofloxacin, d diclofenac, e paracetamol, and f carbamazepine, respectively. Colors indicate the concentration

difference to the background concentration. Dot size scales with sample depth (see also SI Figure S3a-e). The flag indicates the site of the WWTP outlet (color figure online) 


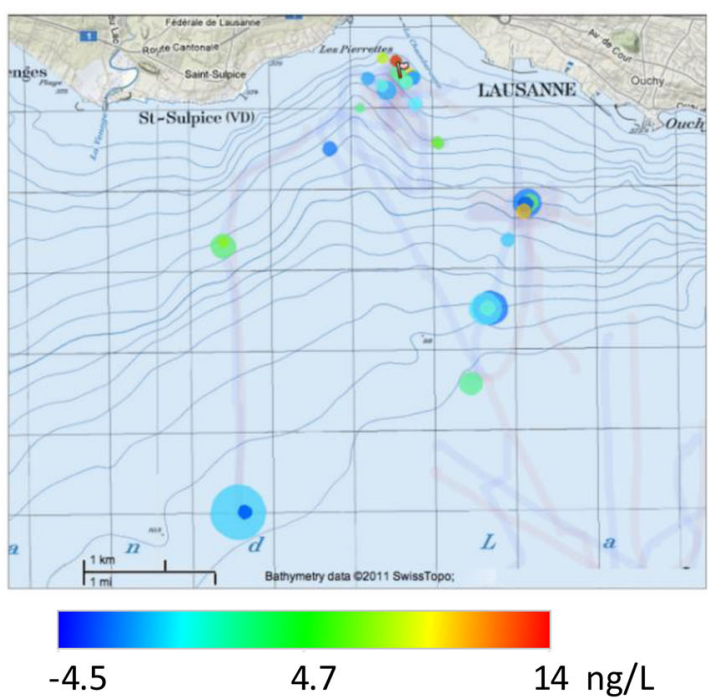

Fig. 4 Difference between measured concentration and background concentration (ng/L) for corrosion inhibitor and pesticides: a atrazine and $\mathbf{b}$ mecoprop. Colors indicate the concentration difference to the

(Fig. 3d). The concentration in this sample lies well above any previously measured concentration of diclofenac at a distance from the wastewater outlet. We therefore believe that this sample may have been contaminated during sample treatment. The change in concentration throughout the Bay, however, varied between substances: the concentration of sulfamethoxazole remained elevated beyond the Bay (Fig. 3a), whereas the concentrations of ciprofloxacin, diclofenac, and paracetamol diminished more rapidly with distance from the WWTP outlet (Fig. 3c-e). Because all compounds are expected to undergo the same extent of dilution, these discrepancies may be explained by differences in their environmental elimination processes. As discussed in detail elsewhere, the most relevant elimination process for the majority of compounds investigated is photolysis (Bonvin et al. 2013). Reported direct photolysis half-lives in different water types and seasons ranged from minutes (diclofenac) to hours (ciprofloxacin) to 2-3 days (sulfamethoxazole) (Hidalgo et al. 1993; Torniainen et al. 1996; Buser et al. 1998; Poiger et al. 2001; Andreozzi et al. 2003; Lam and Mabury 2005; Yang et al. 2008, 2009; Radke et al. 2010; Tong et al. 2011; Bonvin et al. 2013). In addition, the different patterns could stem from temporal variations in the ratio of the different substances in the wastewater. Paracetamol, while less prone to direct photolysis, is rapidly biodegraded by microorganisms (Jones et al. 2007). Differences among the rates and types of degradation processes (biodegradation may occur throughout the water column, while photolysis only takes place in the photic zone) may thus lead to differences in the spatial extent where critical concentrations of the individual substances occur.

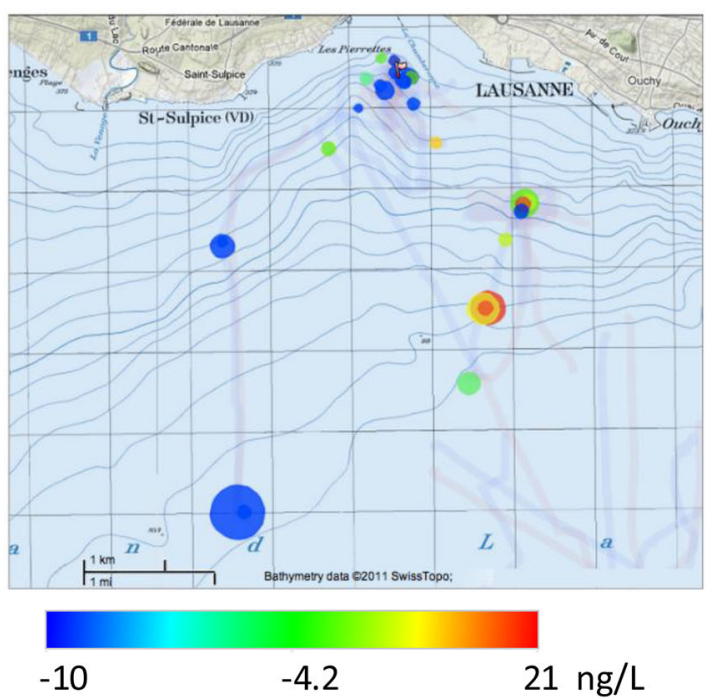

background concentration. Dot size scales with sample depth (see also SI Figure S3a-e). The flag indicates the site of the WWTP outlet (color figure online)

Compared to other pharmaceuticals, the carbamazepine concentrations throughout the investigated area were more homogeneous (Fig. 3f). Near the WWTP outlet, the concentrations were only slightly elevated compared to the background and a decrease with distance from Vidy Bay was not observed. Carbamazepine is produced by several pharmaceutical industries in the Rhone Valley that discharge their effluents into the main tributary of Lake Geneva, the Rhone River. This induces a non-negligible source of carbamazepine into the lake (Bonvin et al. 2011). This compound had higher concentration compared to the background concentration not only near the WWTP outflow but also outside Vidy Bay (Fig. 3f), and hence, the additional input from wastewater was less pronounced. Unlike the other pharmaceuticals investigated, carbamazepine did not primarily stem from the Vidy WWTP. In fact, $>90 \%$ of carbamazepine in Lake Geneva has been estimated to originate from industrial activities in the Rhone River valley, and carbamazepine concentrations up to $1 \mu \mathrm{g} / \mathrm{L}$ have been measured periodically in the Rhone shortly before its discharge into the lake (Bonvin et al. 2011 and references therein. Such high carbamazepine loads lead to sufficiently high background concentrations to mask the additional input from wastewater treatment plants.

As for carbamazepine, the concentrations of pesticides, which are mostly not wastewater-derived, were relatively homogeneous throughout the Bay (Fig. 4a-b). This indicates a constant input of non-wastewater derived compounds that enter the lake via its tributaries or from diffuse sources. The photolysis half-lives of these compounds are comparable to those of pharmaceuticals (from 
hours to days; Konstantinou et al. 2001; Lin and Reinhard 2005; Meunier and Boule 2000).

Correlation of micropollutant concentrations with electrical conductivity

Bonvin et al. (2011) reported a linear correlation between electrical conductivity and the concentrations of wastewater-derived micropollutants in the wastewater-influenced water mass. In contrast, pesticides and carbamazepine exhibited a different trend with insignificant or low correlation coefficients. This finding was reproduced with the data collected in this study: except for carbamazepine ( $p$ value $=0.04$ ), an analysis of covariance showed no significant differences between the dataset presented here and that of Bonvin et al. (2011). This confirms that the measurement of (wastewater-induced) increases in conductivity may serve as an initial indicator to delineate the area where elevated wastewater-derived micropollutant concentrations can be expected. Correspondingly, the area where the greatest pharmaceutical concentration coincides with that of elevated conductivity (Figs. 1, 3).

\section{Ecotoxicological risk assessment}

Due to the wind regime in Vidy Bay, circular currents can retain water and sediment within Vidy Bay (Poté et al. 2008; Razmi et al. 2013). Dissolved micropollutants may thus not be transported out of Vidy Bay, but can instead accumulate within the Bay, raising concerns regarding their ecotoxicological impact. During a sampling campaign in this area from April to October 2010, a RQ $>1$ was identified within the wastewater-influenced water mass for three antibiotic substances (sulfamethoxazole, azithromycin, ciprofloxacin) and throughout the Bay for one pesticide (irgarol) (Bonvin et al. 2011). Hence, an ecotoxicological risk for the aquatic organisms arising from these substances cannot be excluded.

In this study, five individual compounds had a RQ $>1$ (Table 1). In addition to the previously observed antibiotics and pesticides, the concentration of the analgesic diclofenac was found at a concentration exceeding its PNEC (Fig. 2b, SI Figure S4a-d). Four further compounds had RQs within one order of magnitude (RQ $>0.1$ ) of the critical value: clarithromycin, propranolol, carbendazim, and terbutryn (SI Figure S5a-d).

As aquatic organisms are exposed to all micropollutants simultaneously, individual RQs may not appropriately capture the resulting ecotoxicoloigcal effects. Therefore, the cumulative RQ for all substances was also considered. The approach of cumulative RQ assumes that all substances act on aquatic organisms by the same mode of action. While this assumption is likely not fully met in environmental mixtures, this approach has been validated for mixture toxicities (Belden et al. 2007; Cedergreen et al. 2008). Here, the cumulative risk was therefore used as an upper boundary of the total ecotoxicological risk exerted by all substances considered.

Based on the estimated cumulative toxicity of wastewater-derived compounds, an elevated risk was observed within and slightly west of Vidy Bay compared to sampling points towards the east of the Bay (Fig. 5a-b). In 20 (out of 34) samples, the RQ for pharmaceuticals exceeded unity, with a maximal cumulative RQ of $>11$. For non-wastewater derived compounds, the risk was generally lower: an elevated risk was found only once near the WWTP discharge (Fig. 5c-d). This was mostly due to the presence of irgarol, which has a very low PNEC. It should be noted, however, that fewer pesticides than pharmaceuticals were investigated herein; therefore fewer compounds contributed to the cumulative RQ, which may account for the lower values. In fact, another study evaluating the RQ of several herbicides in Lake Geneva reported that metolachlor and foramsulfuron exceeded the RQ of 1 between 5 and 20 times throughout the lake (Chevre et al. 2008).

Given that micropollutants co-occur in the environment, all micropollutants investigated have to be considered jointly. With this approach, a cumulative RQ $>1$ was found in 25 samples (range 1 to 11.45 ; Fig. 5e-f). This demonstrates that the risk exerted by wastewater-derived substances is elevated by the simultaneous presence of micropollutants originating from diffuse sources or tributaries.

\section{Conclusions}

This study demonstrated that wastewater-derived micropollutants can be detected at elevated concentrations in Vidy Bay, Lake Geneva, over the extent of $1 \mathrm{~km}^{2}$ surrounding the WWTP outlet. The location of the wastewater-influenced water mass, delineated by an increase in conductivity compared to the background, coincided with elevated concentrations of wastewaterderived micropollutants. Therefore, conductivity served as a good indicator of a potential ecological risk exerted by micropollutants.

The highest concentrations of individual wastewaterderived substances were measured near the WWTP outlet; however, the zone in which the mixture of all substances posed a potential risk extended well into the lake, in particular in the south/south-western direction. While the low concentrations of micropollutants found in the lake are currently not believed to cause a health problem to humans, it is nevertheless interesting to note that the zone of potential risk reached the vicinity of the St. Sulpice 

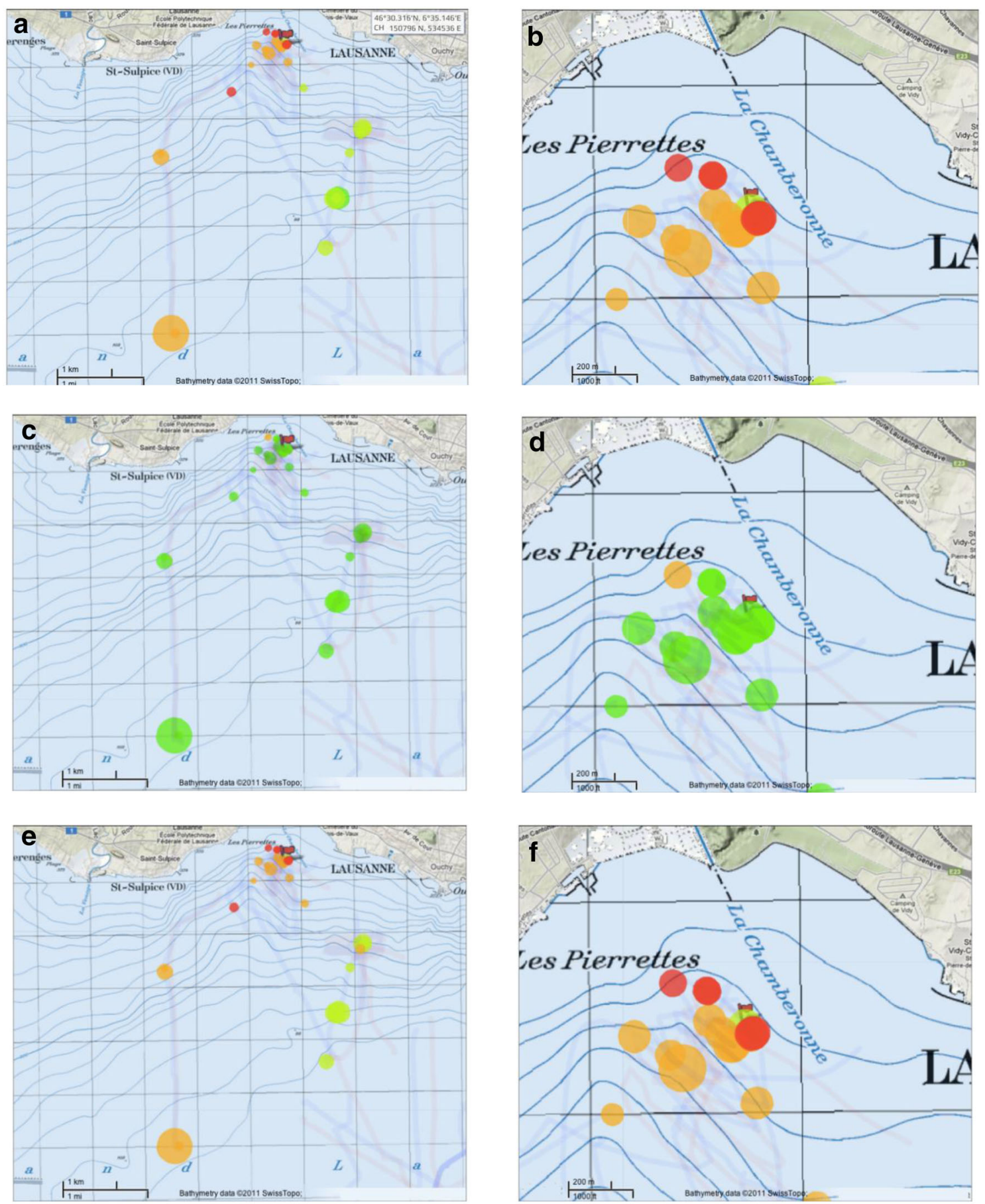

Risk quotient

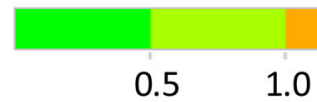

Fig. 5 Risk quotients (RQ) in the sampling area of Lake Geneva (left panel) and Vidy Bay (right panel) of wastewater-derived micropollutants (a, b), non-wastewater-derived micropollutants (c, d), and both combined $(\mathbf{e}, \mathbf{f})$. Colors indicate cumulative risk quotient, RQ. 
drinking water intake, which contributes to the water supply of the city of Lausanne.

Finally, it should be emphasized that the area of the observed wastewater-influenced water mass and ecotoxicological risk represents an overview of multiple observations during the entire sampling campaign. Our study is, however, mainly relevant to the warmer seasons, when lake stratification prevents effective vertical dilution of the wastewater-influenced water mass and micropollutants therein. A better water quality (risk quotient $<1$ ) can be expected in winter, when vertical mixing of the water masses leads to a more efficient distribution of micropollutants throughout the water column.

Acknowledgments This publication is part of the international, interdisciplinary research project ELEMO (http://www.elemo.ch) to investigate the deep-waters of Lake Geneva using two Russian MIR submarines. Funding for this study was provided by the Fondation pour l'Etude des Eaux du Léman (FEEL). Additional funding for the work described in this paper was provided by Swiss National Science Foundation (project no. PDRMP2-123028/1). We are grateful for the support. We thank the Russian MIR crew members (www.elemo.ch/ mir-team) for their excellent performance and the SAGRAVE team who provided and operated the platform from which the dives were carried out. We also thank Ulrich Lemmin and Jean-Denis Bourquin for project coordination and Jean-Luc Loizeau for dive planning. The service of Mikhail Kranoperov (Russian Honorary Consulate) as liaison is greatly appreciated. The authors would like to acknowledge Bernhard Wehrli for providing the SBE.

\section{References}

Akhtman Y, Martelletti L, Grandjean O, Lemmin U (2012) Collaborative Web-GIS platform for systematic exploration of Lake Geneva. International Archives of the Photogrammetry, Remote Sensing and Spatial Information Sciences XXXIX-B4:1-6

Andreozzi R, Raffaele M, Nicklas P (2003) Pharmaceuticals in STP effluents and their solar photodegradation in aquatic environment. Chemosphere 50(10):1319-1330

Backhaus T, Faust M (2012) Predictive environmental risk assessment of chemical mixtures: a conceptual framework. Environ Sci Technol 46(5):2564-2573

Backhaus T, Altenburger R, Arrhenius A, Blanck H, Faust M, Finizio A, Gramatica P, Grote M, Junghans M, Meyer W, Pavan M, Porsbring T, Scholze M, Todeschini R, Vighi M, Walter H, Grimme LH (2003) The BEAM-project: prediction and assessment of mixture toxicities in the aquatic environment. Cont Shelf Res 23(17-19):1757-1769

Belden JB, Gilliom RJ, Lydy MJ (2007) How well can we predict the toxicity of pesticide mixtures to aquatic life? Integr Environ Assess Manag 3(3):364-372

Benotti MJ, Brownawell BJ (2007) Distributions of pharmaceuticals in an urban estuary during both dry- and wet-weather conditions. Environ Sci Technol 41(16):5795-5802

Bonvin F, Rutler R, Chèvre N, Halder J, Kohn T (2011) Spatial and temporal presence of a wastewater-derived micropollutant plume in Lake Geneva. Environ Sci Technol 45(11):4702-4709

Bonvin F, Chèvre N, Rutler R, Kohn T (2012) Pharmaceuticals and their human metabolites in Lake Geneva: occurrence, fate and ecotoxicological relevance. Arch Sci 65:143-155
Bonvin F, Razmi AM, Barry DA, Kohn T (2013) Micropollutant dynamics in Vidy Bay-a coupled hydrodynamic-photolysis model to assess the spatial extent of ecotoxicological risk. Environ Sci Technol 47(16):9207-9216

Buser HR, Poiger T, Muller MD (1998) Occurrence and fate of the pharmaceutical drug diclofenac in surface waters: rapid photodegradation in a lake. Environ Sci Technol 32(22):3449-3456

Carvalho JLB, Roberts PJW, Roldao J (2002) Field observations of Ipanema Beach outfall. J Hyraul Eng ASCE 128(2):151-160

Cedergreen N, Christensen AM, Kamper A, Kudsk P, Mathiassen SK, Streibig JC, Sorensen H (2008) A review of independent action compared to concentration addition as reference models for mixtures of compounds with different molecular target sites. Environ Toxicol Chem 27(7):1621-1632

Chevre N, Loeppe C, Singer H, Stamm C, Fenner K, Escher BI (2006) Including mixtures in the determination of water quality criteria for herbicides in surface water. Environ Sci Technol 40(2):426-435

Chevre N, Edder P, Ortelli D, Tatti E, Erkman S, Rapin F (2008) Risk assessment of herbicide mixtures in a large European lake. Environ Toxicol 23(2):269-277

Coutu S, Del Guidice D, Rossi L, Barry DA (2012) Parsimonious hydrological modeling of urban sewer and river catchments. J Hyd 464-465:477-484

Daughton CG, Ternes TA (1999) Pharmaceuticals and personal care products in the environment: agents of subtle change? Environ Health Perspect 107:907-938

Giger W, Schaffner C, Kohler H-PE (2006) Benzo triazole and tolyl triazole as aquatic contaminants. 1. Input and occurrence in rivers and lakes. Environ Sci Technol 40(23):7186-7192

Goldscheider N, Haller L, Poté J, Wildi W, Zopfi J (2007) Characterizing water circulation and contaminant transport in Lake Geneva using bacteriophage tracer experiments and limnological methods. Environ Sci Technol 41(15):5252-5258

Hartmann N, Erbs M, Wettstein FE, Schwarzenbach RP, Bucheli TD (2007) Quantification of estrogenic mycotoxins at the ng/L level in aqueous environmental samples using deuterated internal standards. J Chromatogr A 1138(1-2):132-140

Hidalgo ME, Pessoa C, Fernandez E, Cardenas AM (1993) Comparative determination of photodegradation kinetics of quinolones. J Photochem Photobiol A 73(2):135-138

Hoerger CC, Wettstein FE, Hungerbuehler K, Bucheli TD (2009) Occurrence and origin of estrogenic isoflavones in Swiss river waters. Environ Sci Technol 43(16):6151-6157

Huntscha S, Singer H, Canonica S, Schwarzenbach RP, Fenner K (2008) Input dynamics and fate in surface water of the herbicide metolachlor and of its highly mobile transformation product metolachlor ESA. Environ Sci Technol 42(15):5507-5513

Jones OAH, Voulvoulis N, Lester JN (2007) The occurrence and removal of selected pharmaceutical compounds in a sewage treatment works utilising activated sludge treatment. Environ Pollut 145(3):738-744

Kolpin DW, Furlong ET, Meyer MT, Thurman EM, Zaugg SD, Barber LB, Buxton HT (2002) Pharmaceuticals, hormones, and other organic wastewater contaminants in US streams, 1999-2000: a national reconnaissance. Environ Sci Technol 36(6):1202-1211

Konstantinou IK, Zarkadis AK, Albanis TA (2001) Photodegradation of selected herbicides in various natural waters and soils under environmental conditions. J Environ Qual 30(1):121-130

Kuemmerer K (2010) Pharmaceuticals in the environment. Annu Rev Environ Resour 35:57-75

Lam MW, Mabury SA (2005) Photodegradation of the pharmaceuticals atorvastatin, carbamazepine, levofloxacin, and sulfamethoxazole in natural waters. Aquat Sci 67(2):177-188

Lin AYC, Reinhard M (2005) Photodegradation of common environmental pharmaceuticals and estrogens in river water. Environ Toxicol Chem 24(6):1303-1309 
Metcalfe CD, Miao XS, Koenig BG, Struger J (2003) Distribution of acidic and neutral drugs in surface waters near sewage treatment plants in the lower Great Lakes. Canada. Environ Toxicol Chem 22(12):2881-2889

Meunier L, Boule P (2000) Direct and induced photo transformation of mecoprop 2-(4-chloro-2-methylphenoxy)propionic acid in aqueous solution. Pest Manag Sci 56(12):1077-1085

Morasch B, Bonvin F, Reiser H, Grandjean D, de Alencastro LF, Perazzolo C, Chevre N, Kohn T (2010) Occurrence and fate of micropollutants in the Vidy Bay of Lake Geneva, Switzerland. Part II: micropollutant removal between wastewater and raw drinking water. Environ Toxicol Chem 29(8):1658-1668

Oulton RL, Kohn T, Cwiertny DM (2010) Pharmaceuticals and personal care products in effluent matrices: a survey of transformation and removal during wastewater treatment and implications for wastewater management. J Environ Monitor 12(11):1956-1978

Perazzolo C, Morasch B, Kohn T, Magnet A, Thonney D, Chevre N (2010) Occurrence and fate of micropollutants in the Vidy bay of Lake Geneva, Switzerland. Part I: priority list for environmental risk assessment of pharmaceuticals. Environ Toxicol Chem 29(8):1649-1657

Poiger T, Buser HR, Muller MD (2001) Photodegradation of the pharmaceutical drug diclofenac in a lake: pathway, field measurements, and mathematical modeling. Environ Toxicol Chem 20(2):256-263

Poté J, Haller L, Loizeau J-L, Bravo AG, Sastre V, Wildi W (2008) Effects of a sewage treatment plant outlet pipe extension on the distribution of contaminants in the sediments of the Bay of Vidy, Lake Geneva. Switzerland. Bioresour Technol 99(15):7122-7131

Radke M, Ulrich H, Wurm C, Kunkel U (2010) Dynamics and attenuation of acidic pharmaceuticals along a river stretch. Environ Sci Technol 44(8):2968-2974

Razmi AM, Barry DA, Lemmin U, Bonvin F, Kohn T, Bakhtyar R (2013) Direct effects of dominant winds on residence and travel times in a wide open lacustrine embayment: Vidy Bay (Lake Geneva, Switzerland). Aquat Sci:this issue

Schenzel J, Schwarzenbach RP, Bucheli TD (2010) Multi-residue screening method to quantify mycotoxins in aqueous environmental samples. J Agric Food Chem 58(21):11207-11217

Sinton LW, Ching SB (1987) An evaluation of 2 bacteriophages as sewage tracers. Water Air Soil Pollut 35(3-4):347-356
Stoob K, Singer HP, Goetz CW, Ruff M, Mueller SR (2005) Fully automated online solid phase extraction coupled directly to liquid chromatography-tandem mass spectrometry-quantification of sulfonamide antibiotics, neutral and acidic pesticides at low concentrations in surface waters. J Chromatogr A 1097(1-2): $138-147$

Thorpe SA, Lemmin U, Perrinjaquet C, Fer I (1999) Observations of the thermal structure of a lake using a submarine. Limnol Oceanogr 44(6):1575-1582

Tian XD, Roberts PJW, Daviero GJ (2006) Marine wastewater discharges from multiport diffusers. IV: Stratified flowing water. J Hyraul Eng ASCE 132(4):411-419

Tixier C, Singer HP, Oellers S, Muller SR (2003) Occurrence and fate of carbamazepine, clofibric acid, diclofenac, ibuprofen, ketoprofen, and naproxen in surface waters. Environ Sci Technol 37(6): 1061-1068

Tong L, Eichhorn P, Perez S, Wang YX, Barcelo D (2011) Photodegradation of azithromycin in various aqueous systems under simulated and natural solar radiation: kinetics and identification of photoproducts. Chemosphere 83(3):340-348

Torniainen K, Tammilehto S, Ulvi V (1996) The effect of pH, buffer type and drug concentration on the photodegradation of ciprofloxacin. Int J Pharm 132(1-2):53-61

Umlauf L, Lemmin U (2005) Interbasin exchange and mixing in the hypolimnion of a large lake: the role of long internal waves. Limnol Oceanogr 50(5):1601-1611

Vandenberg JA, Ryan MC, Nuell DD, Chu A (2005) Field evaluation of mixing length and attenuation of nutrients and fecal coliform in a wastewater effluent plume. Environ Monit Assess 107(1-3):45-57

Wüest A, Anselmetti FS, Arey JS, Ibelings BW, Loizeau JL, Vennemann T, Lemmin U (2013) Into the abyss of Lake Geneva: interdisciplinary field investigations using the MIR submersibles. Aquat Sci:this issue

Yang L, Yu LE, Ray MB (2008) Degradation of paracetamol in aqueous solutions by $\mathrm{TiO}_{2}$ photocatalysis. Water Res 42(13):3480-3488

Yang LM, Yu LE, Ray MB (2009) Photocatalytic oxidation of paracetamol: dominant reactants, intermediates, and reaction mechanisms. Environ Sci Technol 43(2):460-465 